\title{
Distribution of Weed Population in the Costal Rice Growing Area of Kedah in Peninsular Malaysia
}

\begin{abstract}
This study aimed to develop appropriate weed management technology on selected salt tolerant rice variety(s) as well as to develop package of production technologies for rice in saline environments of Malaysia. This study was conducted at 40 different rice fields in 10 blocks of Kedah coastal area of West Malaysia during June-July, 2009 to identify most common and prevalent weeds associated with rice. Fields survey were done according to the quantitative survey method by using $0.5 \times 0.5 \mathrm{~m}$ size quadrate with 20 samples from each field. A total of 42 different weed species belonging to 17 families were identified of which 25 annual and 17 perennial; 9 grassy weeds, 11 sedges and 22 broadleaved weeds. Leptochloa chinensis, Echinochloa crusgalli, Fimbristylis miliacea, E. colona, Cyperus iria, Sphenoclea zeylanica, Cyperus deformis, Oryza sativa spontanea, Scirpus grossus and Jussia linifolia were most frequent species covering more than $50 \%$ fields. Based on relative abundance indices, annuals were more dominant than perennials. Leptochloa chinensis, Echinochloa crusgalli, Fimbristylis miliacea, E. colona were most dominant weed species in the coastal rice field of Kedah.
\end{abstract}

Keyword: Rice, weed, survey, relative abundance, salinity 